\title{
COMUNICAÇÃO E AGROECOLOGIA: O USO DO AUDIOVISUAL PARA UMA PEDAGOGIA INVENTIVA NO EXERCÍCIO DO PROFESSOR AGROECÓLOGO
}

\section{COMMUNICATION AND AGROECOLOGY: THE USE OF AUDIOVISUAL TO AN INVENTIVE PEDAGOGY IN THE EXERCISE OF THE AGROECOLOGIST TEACHER}

\author{
Letícia Castro Simões ${ }^{1}$
}

Resumo: Neste artigo, são apresentadas duas experiências de realização audiovisual por estudantes de Engenharia Florestal da UFRPE sem nenhum contato prévio com o campo cinematográfico. O objetivo é propor uma discussão do uso de ferramentas da comunicação no exercício da pedagogia, partindo da provocação da professora e pesquisadora Virginia Kastrup (2007) em pensar o trabalho do professor sob a ótica da invenção, da "aprendizagem como invenção de problemas". Mais especificamente, o trabalho deseja pensar o termo "professor agroecólogo", analisando o campo da agroecologia como uma via de encontro entre as ciências da terra e as ciências sociais.

Palavras-chave: Invenção. Educação. Audiovisual.

Abstract: This article presents two experiences of audiovisual exercises made by students of Forest Engineering at UFRPE who didn't have any previous contact with the cinema field. The objective is to propose a discussion on the use of communicational tools in the exercise of pedagogy, departing from the provocation of professor and researcher Virginia Kastrup (2007) to think about the teacher's work from the perspective of invention, or, in other words "learning as invention of problems". More specifically, the paper intends to think about the term "agroecologist teacher", analyzing the field of agroecology as a meeting point between earth sciences and social sciences.

Key words: Invention. Education. Audiovisual.

Data de submissão: 28.06 .2021

Data de aprovação: 18.10 .2021

Identificação e disponibilidade:

(https://revista.univap.br/index.php/revistaunivap/article/view/2641,

http://dx.doi.org/10.18066/revistaunivap.v27i54.2641).

\section{INTRODUÇÃO}

O que faz um professor de agroecologia? Essa pergunta talvez já tenha cruzado o caminho de profissionais da área específica de Agroecologia dentro do ambiente acadêmico. Atualmente, o bacharelado na área pode ser encontrado em

\footnotetext{
${ }^{1}$ Mestre em Estudos Contemporâneos das Artes pela Universidade Federal Fluminense (UFF). Estudante de Graduação em Ciências Sociais pela Universidade Federal Rural de Pernambuco (UFRPE), E-mail: leticia.c.simoes@gmail.com.
} 
cinco universidades públicas: Universidade Federal de São Carlos (UFSCAR), Universidade Federal do Rio Grande (FURG), Universidade Estadual da Paraíba (UEPB), Universidade Federal de Alagoas (UFAL) e Universidade Federal da Paraíba (UFPB). Contudo, dentro do ambiente da Comunicação ou, em um aspecto mais amplo, no universo das Ciências Sociais, a discussão sobre agroecologia não havia, ainda, encontrado ressonância.

Diante da realidade brasileira e, afunilando o recorte deste texto, diante da nordestina, uma sociedade marcada por dívidas históricas advindas da colonização e do sistema escravocrata, analisar exemplos concretos de práticas que visem autonomia política e econômica, como as que ocorrem em algumas cooperativas, por exemplo, é pensar outras formas de país. Inclusive, um Brasil que busque uma melhor relação entre o seu ambiente urbano e o rural, tradicionalmente marcado pela ojeriza e pelo abandono.

Como doutoranda em Comunicação e Informação e integrante de um grupo de estudos que pensa a materialidade da comunicação na prática da educação na América Latina ${ }^{2}$, a agroecologia me pareceu, mais do que um campo de trabalho, um espaço aberto a fim de se inscrever uma discussão epistemológica sobre homem e terra, homem e realidade, homem e existência.

Nessa direção, comecei a enxergar a atuação do professor agroecólogo; ou seja, do sujeito que busca trabalhar a educação através de uma pedagogia a fim de reinventar o mundo. Uma educação que visa a liberdade e a autonomia do outro, buscando a sua independência e consequente articulação própria, valorizando seus saberes e experiências, crendo na multiplicidade de existências que formam um indivíduo.

Dentro do pensamento filosófico pós-estruturalista, o indivíduo não é uma coisa fechada; ele é, na verdade, um emaranhado de coisas. O indivíduo é o resultado desse emaranhado, desse rizoma. O termo foi cunhado pelos filósofos franceses Gilles Deleuze e Félix Guattari (1995) e parte da biologia para pensar a forma como as realidades são produzidas. Um rizoma é um mapa de relações imprevistas, forjadas a todo o momento, uma vez que o homem é um ser social, que está a todo o tempo se relacionando com coisas, seres, objetos. É esse mapa, esse rizoma, que constitui o indivíduo.

Cada um de nós é uma multiplicidade de elementos heterogêneos que funcionam em simbiose. Deleuze e Guattari (1995) provocam o leitor a se fazer algumas perguntas: quais foram as coisas que se juntaram, sob qual regime, para produzir o mundo em que vivemos? Se temos a possibilidade de viver em qualquer outro mundo, por que vivemos neste aqui? Ou seja, se não mapeamos os rizomas do poder, dos estados, das instituições, das relações, não saberemos por onde começar a construir um outro mundo. E é preciso crer no mundo, neste mundo. Crer que este mundo existe e que pode vir a ser outra coisa.

Dessa forma, podemos ler a educação como uma pedra fundamental no mapeamento das estruturas de poder. Nesse sentido, pensar uma pedagogia agroecóloga seria se debruçar sobre a realidade do homem agremiando uma noção de liberdade. E como a comunicação poderia ser uma ferramenta pedagógica?

\footnotetext{
${ }^{2}$ Grupo de Estudos Cognições Inventivas e a Materialidade da Comunicação: Na procura de diálogos experimentais $\mathrm{Na}$ América Latina, coordenado pelo professor doutor Óscar Emerson Zuñiga Mosquera, realizado no âmbito da Universidade Federal Rural de Pernambuco, formado por alunos da Graduação, do Mestrado e do Doutorado, com apoio do CAPES através de bolsas PIBIC.
} 


\title{
2 POR UMA PEDAGOGIA AGROECÓLOGA
}

Uma pedagogia pensada a partir da agroecologia ainda não é uma realidade sistematizada. No Brasil, o campo da agroecologia vem estabelecendo seus próprios termos ao longo dos últimos vinte anos, expandindo seu pensamento através das universidades e das discussões na sociedade acerca da sustentabilidade e do cooperativismo, dois temas chaves dentro da nossa atual realidade. Segundo a definição da Universidade do Rio Grande, localizada em São Lourenço do Sul:

\begin{abstract}
O profissional de Agroecologia promove a recuperação e proteção de solos, recursos hídricos e processos ecológicos; a produção ecológica e orgânica; a gestão de propriedades rurais; a formação de associações, cooperativas e redes; a proteção da saúde do trabalhador rural e consumidor; o manejo sustentável de agroecossistemas; e a produção e divulgação de conhecimentos, tecnologias, serviços e produtos da área. (FURG, 2021)
\end{abstract}

O campo de trabalho da agroecologia, contudo, não está restrito ao pensamento do trabalho prático com a terra. A agroecologia se debruça sobre a relação do homem com a terra. Assim, se torna basilar pensar quem é este homem, em que momento histórico ele está situado e como age diante de seu contexto, bem como a efetividade das mudanças neste contexto. No intuito de promover essa discussão, penso, se constitui a figura do professor agroecólogo.

Estudar a atuação do professor agroecólogo é pensar a relação agrônoma de forma extensa, agremiando a agronomia e a ecologia, mas também a comunicação e as ciências sociais. Discutir a relação com o trato da terra de forma ampla, contextualizando-a historicamente, economicamente e politicamente através das diferentes estruturas que a agroecologia assume a partir dos seus diversos contextos. Debater o papel do professor agroecólogo para além de uma posição vertical como agente transmissor de conhecimento, ou seja, como alguém capaz de pensar conjuntamente estratégias de mudança política.

\begin{abstract}
Assim, lembre-se para a configuração desta narrativa, que a agroecologia deriva no final de um pensamento romântico guiado por um ideal de sociedade que luta contra a unidimensionalidade da razão como projeto humano, o individualismo social, o consumo massificado e destrutor instalado pelo capitalismo; diga-se, é uma luta contra a opressão e engano por parte de uma sociedade moderna, racional e capitalista. (MOSQUERA, 2018, p. 143-144)
\end{abstract}

Dessa forma, o cerne da discussão deste artigo é como inserir a prática do professor agroecólogo dentro de um trabalho de reconstrução do imaginário simbólico em um mundo assolado pelas estratégias neoliberais do sistema capitalista. Parte-se aqui de uma discussão sobre o imaginário simbólico do capitalismo como consequência do processo de "desencantamento do mundo", expressão cunhada pelo sociólogo alemão Max Weber pela primeira vez no artigo "Sobre algumas categorias da sociologia compreensiva" (1910) e debatida na segunda versão do livro "A ética protestante e o espírito do capitalismo" (2004).

Em resumo, para o sociólogo, nas sociedades modernas ocidentais, as ideias de mito e magia advindas de práticas ancestrais, habilidades empíricas e transmissão oral de conhecimento foram substituídas por uma noção de mundo construída pela ciência e pela tecnologia, ou seja, uma noção fundamentada na racionalidade como modo único de existência. 
"O desencantamento do mundo" é uma expressão que se refere ao processo subjetivo operado pela religião protestante e, em consequência, pelas práticas econômicas capitalistas, gerando uma sociedade a qual, no lugar do encantamento, trouxe a concretude, no lugar do imaginário, trouxe a matéria-prima. Os deuses não habitam mais o mundo; o que há é tudo aquilo que se pode tocar, produzir, delimitar. A natureza se torna um instrumento de saque e/ou de transformação a partir do momento em que ela não é mais um ente próprio, mas sim algo a ser utilizado pelo homem, o ser racional.

A razão, ou melhor, a racionalização se torna a linha-mestre do pensamento ocidental a partir do século XVIII, após o movimento filosófico e histórico do lluminismo: só posso crer naquilo que pode ser provado, constatado quantitativamente, qualificado cientificamente. A racionalização é um processo de operação da racionalidade onde se perde a capacidade de reflexão; tudo é baseado em um sistema lógico de ação e reação, causa e consequência. A lógica, contudo, não é a quintessência do pensamento humano, mas uma operação da racionalidade do pensamento. O simbólico seria a quintessência do pensamento humano. A literalidade se torna a morte da dimensão simbólica. A racionalidade se torna um processo de seu enfraquecimento. Sem a capacidade de imaginar, de transgredir aquilo que está diante dos nossos olhos, digamos, a capacidade criativa humana se debilita e, em consequência, sua habilidade de pensar e agir em conjunto. Para Max Weber (2004), a operação de "desencantamento do mundo" provocou um desencantamento da natureza, dos corpos, dos deuses a fim de empoderar o pensamento único, a monocultura, o capitalismo, enfim, a concentração de capital na mão de poucos indivíduos - e toda esta operação parecer natural.

Se analisarmos o campo de ação do professor agroecólogo como um ser dotado de subjetividade e em busca de "dialogo direto ao indivíduo com o campo ambiental no intuito de formar um sujeito ecológico" (MOSQUERA, 2018, p. 143), entendendo a ecologia como uma ampla esfera do pensamento que inclui formas de viver no mundo, sendo atravessada pela discussão política e econômica da decolonização, por um lado, e por práticas pedagógicas que visem à libertação de conceitos, abre-se uma discussão sobre o papel do professor agroecólogo nessa possível reconstituição do imaginário simbólico em um mundo assolado pela lógica da razão e da produtividade.

Como aponta Vilém Flusser:

\begin{abstract}
Todo (ou praticamente todo) pensamento filosófico ocidental está viciado por um ódio fundamental à natureza. A história do Ocidente é a história progressiva desse ódio. É a progressiva profanação da natureza. Em seu ódio à natureza, em seu esforço de humilhá-la, o homem ocidental se afasta dela e se opõe a ela.[...] A natureza se transforma em sistema de coisas, cada qual com seu lugar fixo. (FLUSSER, 2002, p. 108-109).
\end{abstract}

Podemos observar, assim, a importância do pensamento agroecólogo e sua atividade no momento presente, ainda mais quando efetivamos o nosso recorte espacial: o Brasil, país da América Latina, continente marcado por uma história de violência colonial e intervenções políticas de cunho neoliberal. Assim, o foco desse texto parte de um questionamento: como pode um professor agroecólogo agir diante de um mundo desencantado? 


\section{O ENSINO COMO INVENÇÃO}

Como dito anteriormente, a agroecologia pressupõe o diálogo com outras áreas do conhecimento, a partir de um entendimento amplo da relação entre homem e natureza. Nesse percurso, atravessa as ciências sociais, o direito, a comunicação, a filosofia para "contrastar os exercícios de assujeitamento que envolvem os indivíduos, no seu self e na sua formação profissional, com uma ontologia da diferença que leve a uma espiritualidade política" (MOSQUERA, 2018, p. 144).

O professor agroecólogo em seu exercício pedagógico, assim, tem como desafio pensar outras formas de se constituir enquanto sujeito visando a manutenção do debate sobre as nossas realidades política e econômica, bem como as estratégias presentes em cada comunidade para dar conta de uma outra possibilidade de futuro, pensada e moldada pelos agentes da terra, aqueles que lidam cotidianamente com ela.

Nesse sentido, trazemos à discussão a proposta da aprendizagem como invenção, e da invenção como "condição de possibilidade da liberdade", propostas pela psicóloga Virginia Kastrup. Em seu livro "A invenção de si e do mundo", Kastrup apresenta seu trabalho como uma atividade filosófica que se debruça sobre o estudo da subjetividade. A filosofia, para ela, está posta como uma operação de questionamento das situações estabelecidas historicamente ${ }^{3}$.

Para Kastrup, estudar a subjetividade humana é uma prática ligada a estudar formas de vida, propondo outras possibilidades de existência, partindo do pressuposto de que a forma como vivemos está diretamente ligada à forma como compreendemos 0 mundo ${ }^{4}$. Podemos fazer uma ligação direta entre a teoria de "desencantamento do mundo" de Max Weber ${ }^{5}$ e a proposta de Virginia Kastrup: a

\footnotetext{
${ }^{3}$ Virginia Kastrup está conceituando a prática filosófica. Para o filósofo Gilles Deleuze, por exemplo, o trabalho da filosofia está em criar conceitos. Para Michel Foucault, a prática filosófica envolveria questionar os conceitos estabelecidos de "verdade" e "poder", definidores da vida humana. Para efeitos deste artigo, partindo da visão de Kastrup, podemos fazer um paralelo com os estudos contemporâneos de História Social do Brasil, bem como das Ciências Sociais Brasileiras, realizadas a partir das décadas de 1980 e 1990, quando do fim do regime civil-militar que perdurou por 25 anos. Um dos marcos da subjetividade ditatorial - seja ela qual for - é a reescrita da história a partir da ótica vigente, a do dominador. No caso brasileiro, por exemplo, os primeiros cursos de pós-graduação em ciências humanas foram criados no fim da década de 1970, e os acessos a importantes documentos que vão resvalar em pesquisas questionadoras do nosso status-quo só vão ser permitidos no fim da década de 1980, a partir da pressão dos movimentos sociais. Essa reconfiguração do pensamento vai gerar um questionamento das situações estabelecidas historicamente, bem como do ensino destas questões, como por exemplo, a própria situação ditatorial.

${ }^{4} \mathrm{O}$ entendimento de Kastrup sobre pedagogia e formas de ensino pode remeter, para algumas pessoas, ao projeto pedagógico iniciado pelo pernambucano Paulo Freire. Freire pensava a educação como prática da liberdade, foi visto como uma ameaça pela ditadura, perseguido e exilado do país. Freire era contra o que chamou de "educação bancária", onde o professor é responsável único pela transmissão unilateral de conhecimento e os alunos, disciplinados física e subjetivamente, seriam meros depósitos de conhecimento. $O$ ensino existe pela e através da experiência, segundo Freire. Existe, contudo, uma diferença fundamental entre suas linhas de pensamento: Freire está inscrito em um contexto histórico e filosófico que pressupõe a unidade do sujeito para pôr em debate suas práticas. Kastrup está inserida em um pensamento pós-estruturalista onde um de seus pilares é justamente o questionamento dessa unidade ontológica.

${ }^{5}$ Também é válido sublinhar que a tese de Weber se debruça sobre relação entre a ética protestante e o desenvolvimento do capitalismo; para o sociólogo, o fato da religião protestante ter como parte de seus dogmas a austeridade individual, a dedicação ao trabalho e o enriquecimento como um sinal da escolha divina, no continente europeu, teria provocado o estabelecimento do capitalismo como modelo econômico preponderante.
} 
partir de uma crença desmedida na racionalidade como única via de se relacionar com a realidade, a nossa subjetividade se afasta da dimensão imaterial e sem um fim prático, tendendo a somente valorizar aquilo que é voltado à produção, ao enriquecimento, à transformação material.

A vida é, antes de tudo, um impulso vital, um élan, uma tendência simples e criadora, que só se atualiza por uma articulação ou uma mistura com uma outra tendência, que é a matéria. Essa maneira de pensar correlaciona-se diretamente com a definição do vivo através de uma capacidade de pôr e solucionar problemas e não através da categoria negativa de necessidade. Problematizar é bifurcar, criar caminhos divergentes, ao passo que solucionar problemas é ser capaz de viabilizar novas formas de existência. (KASTRUP, 2007, p. 108).

O que a autora nos traz é a ideia da invenção, da criação de problemas como o mote da educação. Problema, aqui, é visto como uma perturbação. Um organismo em (aparente) equilíbrio é perturbado por uma outra força: como vai reagir este organismo perturbado? Vai se adaptar, combater, traduzir, repelir? A situação transforma-se em um problema e as respostas a esse problema se tornam a capacidade de invenção. Kastrup parte da biologia para falar de educação.

A cognição, a nossa capacidade de adquirir conhecimento, seria potencializada através da atividade inventiva, da inscrição da aprendizagem no corpo, da coordenação entre subjetividade e meio através da própria experiência individual. Dessa forma, o aprendizado se faz através da capacidade inventiva, ativada quando se está diante de problemas, sem a crença de que é necessário chegar a um fim resoluto, mas compreendendo a importância da experiência do sujeito em agir, bifurcar-se, adaptar-se e surpreender-se.

O melhor aprendiz não é aquele que aborda o mundo por meio de hábitos cristalizados, mas o que consegue permanecer sempre em processo de aprendizagem. O processo de aprendizagem permanente pode, então, igualmente, ser dito de desaprendizagem permanente. Em sentido último, aprender é experimentar incessantemente, é fugir ao controle da representação. Impedir que a aprendizagem forme hábitos cristalizados (KASTRUP, 2007, p. 132).

\section{A PRÁTICA DA INVENÇÃO: UMA EXPERIÊNCIA A PARTIR DE COMUNICAÇÃO E EXTENSÃO RURAL}

Em 2020, convidada pelo professor Óscar Mosquera, participei como professora da disciplina Comunicação e Extensão Rural da Universidade Federal Rural de Pernambuco. A matéria, ministrada para alunos de Engenharia Florestal, se propôs a pensar formas de ações comunicativas dentro do universo do curso.

Como profissional do audiovisual, tendo me especializado na área do documentário, busquei discutir com os estudantes as particularidades e potências da realização audiovisual de não-ficção. Em termos de metodologia pedagógica, foram realizados três encontros assíncronos de teoria expositiva sobre narrativa audiovisual e outros seis encontros síncronos onde os projetos dos estudantes foram debatidos e acompanhados pela turma até a sua finalização total. No presente texto, serão analisados dois vídeos participantes da disciplina. Contudo, antes de adentrar especificamente a prática empírica, é preciso trazer à tona o contexto brasileiro da relação entre a prática educativa e uma prática de comunicação pela 
produção de imagem e som.

O diálogo entre a educação e o audiovisual no Brasil não é recente: data de 22 de novembro de 1928 o Decreto 2940 que determinava a instalação de salas destinadas à projeção cinematográfica nos edifícios da rede pública, onde o cinema seria "[...] utilizado exclusivamente como instrumento de educação, como auxiliar de ensino que facilite a ação do mestre sem substituí-lo; o cinema utilizado sobretudo para o ensino científico, histórico e geográfico". E, em 2014, através da Lei 13.006, de 26 de junho, foi tornada obrigatória a utilização de duas horas de produção audiovisual brasileiras nas escolas públicas.

Observamos, portanto, que há uma preocupação longeva do Estado brasileiro em unir o audiovisual à prática educacional, mas, também, que esta se reduz à exibição de conteúdo previamente produzido sem uma inicial distinção entre a inserção estrangeira e a nacional (ou, algo possível de imaginar, mas nunca concretizado, um diálogo com o cinema latino-americano), que só vai acontecer com um espaço de quase noventa anos entre a publicação dos dois decretos.

Contudo, nessas nove décadas, entre 1928 e 2014, a tecnologia envolvida na produção audiovisual muito se diversificou, tornando a captação e a edição de vídeos um processo mais barato e, de certa forma, unificado, o qual depende, muitas vezes, de somente um aparelho, como um telefone ou uma pequena câmera digital. Esses aparelhos se tornaram acessíveis economicamente, até por sua função principal ser o registro doméstico, mas também, é possível acompanhar, esses telefones e câmeras vêm se tornando instrumentos potentes na comunicação e consequente construção da identidade adolescente e jovem.

A pesquisadora Eloíza Pires (2010) defende que, com a ampliação tecnológica efetivada no século $X X$, as possibilidades de práticas educativas foram ampliadas, permitindo tanto novas formas de apreensão de conhecimento como também de entendimento de si e das relações. "[...] o tempo e o espaço são reelaborados, produzindo novas formas de relacionamento entre as pessoas. Estas continuam buscando um sentido para sua existência que, para Bakhtin (2003), é encontrado nas relações estabelecidas por intermédio da linguagem, portanto na comunicação" (2010, p. 283).

Destarte, podemos mencionar quatro momentos na democratização da produção de cinema: a introdução das câmeras de $16 \mathrm{~mm}$ como o primeiro marco de produção, seguida da invenção das conhecidas Super 8, a introdução do vídeo e, agora, não apenas um movimento de democratização, mas ainda um momento de popularização do cinema com a chegada dos celulares, cujas câmeras alcançam qualidades profissionais (DARONCO; TOMAIM, 2016). É nesse percurso tecnológico revolucionário que alguns filmes tiveram uma função importante na formação de identidades coletivas. Um caso que tem chamado nossa atenção poderosamente é o filme "A vida do solo" da engenheira agrônoma Ana Primavessi.

Mesmo com a importância desse tipo de produção, cabe a pergunta "onde se mantêm vivas as lembranças da experiência do cinema"? Uma via seria a recuperação da tradição oral, através do testemunho da realização ou da visualização de tais produções. Embora importante esse caminho, aqui consideramos o espaço educativo como possibilidade de duplamente amplificar esse percurso aberto pelo filme "A Vida do solo". A duplicidade vem aqui representada, pois, de um lado temos a imersão do cinema, e de outro, os temas relativos ao sistema agroalimentar, à agroecologia, à produção de alimentos, enfim, à vida vinculada ao mundo camponês geralmente invisibilizado. 
Se a memória é potência, assim é possível afirmar que a lembrança narrada de um filme é também a recuperação da potência que a agroecologia, em seus primórdios, tem oferecido para diferentes áreas; ela opera como uma espécie de tensionador que, por exemplo, no caso do cinema de $16 \mathrm{~mm}$, deslocou a dita tecnologia para a "preservação da memória familiar e como catalisador de encontros felizes” (BLANK, 2015, p. 36 apud DARONCO; TOMAIM, 2016, p. 116).

De tal forma, a nosso ver, o filme em questão supera essa classificação proposta por Daronco e Tomaim (2016), que o localiza dentro das produções de cunho educativo, pois, sendo pioneira no uso da tecnologia $16 \mathrm{~mm}$ e no paradigma agroecológico, a professora e agrônoma Ana Primavessi fez ainda uma contribuição incalculável para a sociedade em geral, ao realizar um filme sobre o tema da agricultura ecológica, sem ser formada na área de comunicação e sem ser especialista em cinema. A seguinte citação, ainda que longa, é importante, pois recupera um momento histórico, não só no Brasil, mas em toda América Latina:

A outra apropriação foi a realização do documentário de animação A vida do
solo. O filme começou a ser planejado pela professora de Agronomia da
Universidade Federal de Santa Maria Ana Primavesi em 1963. Ele foi a
primeira produção com essas características na América Latina, além de ser
o primeiro documentário do mundo a tratar do tema da agroecologia. É
preciso destacar aqui que Ana Primavesi é considerada a Mãe da
Agroecologia. Em entrevista, Primavesi lembrou que enfrentava duas
dificuldades em sua rotina, na época. A primeira delas era a barreira do
idioma. De origem austríaca, até hoje a idosa mescla palavras em
português e alemão. A segunda era como explicar um conceito criado por
ela e que causava uma série de desconfianças: 'Naquela época era normal
que a gente tentasse buscar alternativas para mostrar às pessoas o que
queríamos dizer com determinados conceitos. Porque era tudo muito novo.
As pessoas nem sempre entendiam o que queríamos dizer quando
falávamos que havia vida no solo [...]. A gente primeiro falou em desenhar o
que queríamos mostrar. A ideia de fazer um filme surgiu depois. Eu fiz um
roteiro e o Orion fez os desenhos. Ele ajudou muito me dizendo como se
fazia um roteiro, como ficava melhor. Porque ele tinha ideia de como se
fazia, de como executar. Eu fiz o roteiro, mas ele que sabia como se fazia
um filme (DARONCO; TOMAIM, 2016, p. 118).

Desde esse acontecimento da imagem elaborado pela professora Primavessi, muitas experiências e propostas foram criadas usando o cinema na promoção de temas dentro da matriz agroecológica. A exemplo disso, mencionamos os trabalhos de Pinheiro e Guimarães (2017), os quais apresentam o uso pedagógico nas ciências agrárias das chamadas Tecnologias Educacionais em Rede (TER), em especial, o uso do vídeo como elemento que media a relação ensino-aprendizagem, levantando assim uma reflexão sobre as práticas docentes e os fundamentos epistemológicos das Ciências Agrárias na educação formal superior.

Medeiros (2018) destaca as diferentes estratégias utilizadas nos documentários que visam diferenciar a agricultura de base agroecológica da convencional ou industrial, criando-se assim uma formação discursiva antiagricultura industrial. Estudos como estes apresentam uma poderosa ferramenta a ser trabalhada na educação toda vez que, com seu viés pós-estruturalista, a pesquisa visualiza as relações de poder que o saber ambiental veicula nas produções audiovisuais. Como evidenciamos, a relação cinema-educação no cenário ambiental, ecológico ou agroecológico, apresenta uma ampla possibilidade de análise e discussão.

Justamente a forma documental foi a escolhida para ser trabalhada com a 
turma de Engenharia Florestal da Universidade Federal Rural de Pernambuco UFRPE, a fim de serem desenvolvidas narrativas agroecológicas desde o campo de trabalho de cada um dos grupos. A escolha pelo modo documental como foco de estudo foi pensada tanto no sentido prático, por compreender que a assimilação audiovisual do dito "cinema do real" é próxima à realidade dos alunos, acostumados a deparar-se com documentários sobre o cotidiano da Engenharia Florestal, mas também pelo desejo de pôr em prática o que seria esta pedagogia da invenção ou, como praticar a invenção tendo como base primeira, dados concretos do material cotidiano.

O gênero "documentário" foi cunhado no início do século XX em oposição ao cinema tido como ficcional; se no segundo ambiente, há o emprego de atores, figurinos, cenários no intuito de criar uma narrativa com início, meio e fim, na prática documental, partir-se-ia da realidade para dar conta de uma determinada questão. Falo no condicional por um dado: desde o início, o modo de registro documental não quer dizer, imediatamente, uma apreensão cabal da realidade ${ }^{6}$.

Dessa forma, busquei debater com a turma os conceitos de "verdade" e "realidade", e como o que é tido como um gênero cinematográfico, o documentário, pode ser melhor encarado como uma forma dentro da realização audiovisual. Algo que parte de um dado real para circulá-lo, questioná-lo, mostrar a sua visão própria sobre este ou aquele fato. Os três encontros realizados de forma virtual sobre o modo de pensar a escritura do documentário foram pensados em termos de provocações; num diálogo com Kastrup, poderiam ser melhor vistos como apresentações de problemas mirando não a solução deles em um formato audiovisual, mas uma compreensão dos alunos sobre a realidade deste problema resultando em uma resolução subjetiva audiovisual.

Um aspecto abordado no primeiro encontro, por exemplo, foi a relação entre potência e necessidade dentro da abordagem documental. Ao invés de trabalhar com conceitos estáticos, como a fórmula o quê, quando, onde, quem e por quê se está falando em um documentário - método importado das redações jornalísticas norte-americanas e implantado em algumas escolas de escrita documental -, preferi seguir com provocações sobre os conceitos de potência e necessidade, sendo a primeira a relação da ideia documental com o mundo exterior, e a segunda, com o mundo interior. Da potência, se pergunta: O que se espera de documentário? Qual olhar o documentário lança ao mundo? Quem está falando? De que modo posso contar essa história para que ela se torne única? E da necessidade: De onde estou falando? Quem sou eu? Qual história que somente eu posso contar? Desafiada por Kastrup e Flusser, e com a noção de "desencantamento do mundo" muito próxima, as discussões tentavam chamar os estudantes não versados na prática cinematográfica a inventar novos problemas sobre as questões postas.

A turma de 19 alunos foi dividida em duplas e trios. Na data acertada entre todos, houve a apresentação das ideias para futuros documentários: dois

\footnotetext{
6 "Nanook, o esquimó", dirigido por Robert Flaherty, e tido pelos anais cinematográficos como o primeiro longa-metragem documental da história do cinema ao narrar o cotidiano de Nanook, um esquimó de Port Huron, no Canadá, e sua família, é, na verdade, uma refilmagem ficcional. Flaherty havia viajado um ano antes para a região e pesquisado sobre as formas de vida, moradia, caça, relacionamento dos esquimós. Sob o pretexto de que suas filmagens originais haviam se perdido em um acidente no laboratório de revelação, Flaherty retorna às filmagens com uma proposta narrativa onde realidade e ficção se mesclam ao ponto dele utilizar sua então esposa como atriz no documentário.
} 
estudantes, Wilson e Gustavo ${ }^{7}$ queriam abordar a LGBTQIA+fobia dentro do ambiente do ensino público universitário da Engenharia Florestal, segundo eles, tradicionalmente masculino. Ambos são homens gays e partilharam situações onde sentiram o preconceito, desde o questionamento de um professor sobre a escolha do curso até nas situações de estágio, em convívio com outros colegas.

Para Wilson e Gustavo, era fundamental contar com as partilhas de outros estudantes do mesmo curso, mas devido à pandemia do COVID-19, ir de encontro a outras pessoas tornou-se uma situação de risco. Assim, a dupla propôs encontros virtuais gravados através da plataforma Google Meet, onde os personagens dialogam com os interlocutores que, através da montagem, cruzam situações semelhantes em distintos contextos, conseguindo integrar, inclusive, alunos de outros estados (Universidade Federal do Maranhão, do Piauí, do Ceará e da UFPE).

No encontro posterior para uma avaliação do vídeo de 30 minutos entregue - a proposta inicial era de um curta-metragem com, no máximo, 5 minutos -, Wilson e Gustavo partilharam da excitação em entrevistar pessoas que não conheciam pessoalmente e conduzir a filmagem sem perder o foco do que eles estavam tentando transmitir, a ideia da quebra de um paradigma da Engenharia Florestal, um suposto curso dominado por homens heterossexuais e brancos, advindos de uma classe social mais abastada. A partir da pesquisa dos personagens e dos relatos de suas experiências, motivadas pela pergunta "por que você decidiu cursar Engenharia Florestal?", deu-se vazão a um panorama mais múltiplo em termos de gênero e raça e que busca se apoiar e se reinventar diante de situações de preconceito.

Outro exemplo foi o curta-metragem de animação "Em chamas, um paraíso de cinzas", de Maria Eduarda Fernandes e Yasmin Araújo. As alunas compartilharam do desejo de discutir os incêndios ocorridos no Pantanal em 2020, não de uma perspectiva demarcada temporalmente - as queimadas daquele específico ano mas como um problema endêmico brasileiro, situando-o historicamente. Yasmin debateu em aula a sua necessidade de uma preocupação menos imediata e mais ampla com o ecossistema pantaneiro, tanto pela imensidão da tragédia quanto pela possível repetição do cenário de devastação nos próximos anos. Era preciso, com o vídeo, promover um alerta para o futuro. O mesmo problema de Wilson e Gustavo, o impedimento do contato físico devido à pandemia, se apresentou a Maria Eduarda e Yasmin; as estudantes também recorreram à estratégia da entrevista on-line, mas abordada de outra forma.

Inicialmente, no vídeo, acompanhamos as manchetes mais recentes à época, abordando o desastre ambiental e suas consequências a longo prazo. Em seguida, elas apresentam manchetes de anos anteriores que também denunciam incêndios no Pantanal. Ouvimos uma voz: trata-se de Alexandre Pereira, analista ambiental do IBAMA, do setor de Prevenção ao Fogo, do departamento de Mato Grosso do Sul. Pereira, ao longo dos 15 minutos de vídeo, faz uma apresentação agroecológica do Pantanal, tratando de suas fronteiras biológicas, geográficas, políticas e econômicas. Para o analista, as queimadas decorreram de uma tríplice causa: a seca intensa, que persistia desde 2019 na região, as temperaturas acima da média e a não cheia do rio Paraguai "criaram um cenário perfeito para os incêndios florestais" (2020, minuto 04:31). A estiagem iniciada no ano anterior foi agravada pela ação humana através da criação de gado e pelo desmatamento, com a exploração ilegal

\footnotetext{
${ }^{7}$ Os nomes foram alterados para preservar a identidade dos alunos e respeitar a privacidade do conteúdo trocado dentro da sala de aula.
} 
de madeira. O aumento da temperatura também está ligado ao aquecimento global, provocado ainda pela máquina demolidora humana, com suas emissões intensas de gás carbônico na atmosfera a serviço de uma eterna ideologia do progresso. Para Pereira (2021), por fim, "95\% a 98\% dos incêndios de 2020 têm como origem a ação humana", o que liga um alerta sobre o futuro do Pantanal. Como deter o homem?

Seguimos a fala do analista ambiental, todavia não vimos seu rosto. Ficamos, ao longo de treze minutos, com uma aquarela em movimento, uma expressão artística das duas realizadoras, que pintaram o ecossistema do Pantanal para, ao fim da fala de Pereira, queimá-lo. O vídeo, por fim, é dedicado àqueles que, no momento, estavam lutando para salvar a vida ainda existente no ambiente pantaneiro.

Ao conversar com Yasmin sobre a realização do vídeo, a aluna explicitou que buscava "uma via mais poética para tratar de um tema tão árido". Em sua visão, um dos problemas na prática comunicacional da Engenharia Florestal está em seus interlocutores se aterem a uma linguagem técnica, entendida somente por aqueles que possuem interesse e conhecimento prévios no assunto.

\section{CONCLUSÃO}

Se vivemos em um mundo desencantado, onde a racionalização tomou conta não só dos processos práticos, mas também da experiência subjetiva enquanto sujeitos da história, torna-se parte da atividade pedagógica do professor agroecólogo discutir as vias de reconhecimento dessa operação e as possibilidades da criação de práticas outras. Busca-se uma pedagogia que partilhe a ideia da integração do homem com o meio através de provocações e atuações outras que não só as advindas da racionalidade. Uma pedagogia que compartilhe experiências de vida visando a uma transformação política.

"Conhecer é viver. Se o viver é autopoiético, a cognição deve ser dita invenção" (KASTRUP, 2007). Partiu-se da proposta de Virginia Kastrup para encarar a educação como uma atividade inventiva, almejando não a resolução final de problemas, mas a descoberta de novas questões, a partir dos caminhos traçados por cada sujeito conhecedor. O conhecimento é único, na medida em que cada experiência é una, e será atravessada pela poiesis própria de cada um, dando uma ênfase no processo de construção da subjetividade.

Como proposta prática desta discussão teórica, trouxe neste artigo duas experiências de realização audiovisual por estudantes de Engenharia Florestal sem nenhum contato prévio com este campo. Dentro da matéria de Comunicação e Extensão Rural da Universidade Federal Rural de Pernambuco, realizada no PLE (período letivo especial) 2020.3, os alunos foram instigados a realizar um curtametragem em documentário de até cinco minutos.

O primeiro vídeo citado trouxe a experiência de dois estudantes gays dialogando com relatos de colegas de Engenharia Florestal de outras universidades públicas nacionais, a partir da ótica da vivência LGBTQIA+. Tendo como ótica primeira suas corporalidades no mundo, eles partilharam, através de encontros filmados via plataforma digital, afetos, dúvidas e possíveis caminhos de legitimação de suas batalhas dentro do universo acadêmico.

A realidade LGBTQIA+ é permeada pelo preconceito e pela discriminação. Pela falta de visibilidade. Em um exercício fílmico, baseado em uma pedagogia da invenção, se buscou construir uma outra partilha de significados individuais; tecer 
uma rede simbólica em que diferentes tramas de vivências se coligam, compactuando-se para uma outra narrativa desses estudantes da Engenharia Florestal. Existem, sim, alunos e alunas LGBTQIA+ neste curso e eles falam. Suas palavras invadem o mundo. Através do vídeo construído, foram levantadas soluções práticas para o sentimento de solidão dos estudantes, como a criação de centros de apoio dentro das universidades públicas que hoje não contam com essa possibilidade (como o caso da UFRPE), em relação direta com as universidades que possuem tais iniciativas (como o caso da Universidade Federal do Ceará - UFC). Também foram apresentadas cooperativas existentes e ativas atualmente no Nordeste, cujos integrantes são trabalhadores rurais LGBTQIA+. Como exemplo específico, citou-se a cooperativa de mulheres lésbicas de Aldeia, macrorregião do Recife, dedicadas à plantação de cogumelos. Aventou-se a possibilidade de, em um período pós-pandêmico, realizar um documentário com esta experiência.

No segundo vídeo, as alunas abordaram um problema caro à Engenharia Florestal, as queimadas no Pantanal, mas sob uma abordagem artística, buscando imprimir um cunho poético à discussão científica. Ao trazer a prática da pintura em aquarela para o vídeo, Yasmin e Maria Eduarda empregaram suas subjetividades em um exercício inventivo de produção de conhecimento sobre a realidade. As alunas partiram de um tema traumático no campo do trato do homem com a terra, as queimadas do Pantanal, para expandir o campo de pensamento, reflexionando sobre a histórica relação do homem com a natureza que, segundo Weber (2004), a partir do processo de desencantamento do mundo, vem sendo tratada de forma mercadológica e objetificada. Yasmin e Maria Eduarda buscaram, em seu documentário de animação, sensibilizar uma percepção contemporânea do que seria a atuação humana diante do mundo que está à frente. Se temos sensibilidade à arte, por que não a estendemos à natureza? Está mais do que na hora de repensarmos essa relação desencantada - e é disto, ao fim, que este curta documental trata.

Pensar a educação nos termos da escuta e do afeto é discordar de práticas colonizadoras que, historicamente, cerceiam a liberdade de pensamento e de construção de subjetividades, impondo uma submissão do pensar, do agir político e do entorno econômico a uma ordem vigente que não nos corresponde. Torna-se urgente abrir arestas para o respirar da prática educativa, visando à autonomia dos indivíduos e o reconhecimento da diferença de cada um frente ao outro. Talvez, dessa forma, se possa caminhar em direção ao que se cogita ser um reencantamento do mundo.

\section{REFERÊNCIAS}

BAKHTIN, Mikhail M. Estética da criação verbal. São Paulo: Martins Fontes, 2003.

DARONCO, Marilice Amábile Pedrolo; TOMAIM, Cássio dos Santos. Memórias em frames: o suporte $16 \mathrm{~mm}$ e a experiência de fazer cinema. Pós, Belo Horizonte, v. $6, \mathrm{n}$. 12, p. $110-125,2016$.

DELEUZE, Gilles. GUATTARI, Félix. Mil Platôs. Rio de Janeiro: 34 ed., 1995.

FLUSSER, Vilém. Da religiosidade: a literatura e o senso de realidade. São Paulo: Escrituras, 2002. 
FURG - UNIVERSIDADE FEDERAL DO RIO GRANDE. Graduação. Agroecologia. [2021]. Disponível em: https://www.furg.br/graduacao/agroecologia. Acesso em 16 set. 2021.

KASTRUP, Virginia. A invenção de si e do mundo. Belo Horizonte: Autêntica, 2007.

MEDEIROS, Priscila Muniz. Imagem e discurso: a construção visual da diferenciação entre agricultura industrial e agroecológica em documentários ambientais. DOC Online: Revista Digital de Cinema Documentário, Covilhã, n. 23, p. 158-173, 2018. DOI: 10.20287/doc.d23.ar04

MOSQUERA, Oscar. Virada ecológica e ecogovernamentalidade: uma analítica foulcatiana do sujeito ecológico na agroecopedagogia pernambucana. 2018. $214 \mathrm{f}$. Tese (Doutorado em Educação) - Universidade Federal de Pernambuco, Recife, 2018.

PEREIRA, Alexandre. Em chamas, um paraíso de cinzas. Roteiro: de Maria Eduarda Fernandes e Yasmin Araújo. Recife: [s.n.], 2020. 1 vídeo (15:35min). Disponível em: https://www.youtube.com/watch?v=vex617mrw34. Acesso em: 16 set. 2021.

PIRES, Eloiza. A experiência audiovisual nos campos educativos: possíveis intersecções entre educação e comunicação. Educação e Pesquisa, São Paulo, v. 36 , n. 1, p. 281-295, 2010.

PINHEIRO, Rogério Oliveira; GUIMARÃES, Gisele Martins. Tecnologias educacionais em rede como mediadoras do ensino-aprendizagem da Agroecologia: produção e uso do audiovisual nas ciências agrárias. Extensão Rural, v. 24, n. 3, p. 104-121, 2017.

WEBER, Max. A ética protestante e o espírito do capitalismo. São Paulo: Cia. Das Letras, 2004. 